\title{
Luces y sombras: Boscán en las Anotaciones de Herrera
}

\author{
Javier Lorenzo \\ East Carolina University \\ lorenzoj@ecu.edu
}

Recepción: 01/05/2013, Aceptación: 04/06/2013, Publicación: 20/12/2013

\begin{abstract}
Resumen
El presente artículo examina la recepción de Boscán en las Anotaciones de Herrera, prestando especial atención al proceso de postergación cronológica al que es sometido el verso del barcelonés en el «discurso» sobre el soneto, donde resulta palpable la deuda de Herrera con el vocabulario y los métodos de periodización de la historiografía humanista. El artículo analiza también algunos aspectos de la textura retórica, genérica e intertextual de los dos sonetos «en la muerte de Garcilaso» que Boscán escribe como cierre a su cancionero petrarquista, poemas que Herrera alaba en sus Anotaciones.
\end{abstract}

Palabras clave

Boscán; Herrera; Garcilaso de la Vega; periodización; soneto

\begin{abstract}
Lights and Shadows: Boscan in the Annotations of Herrera

This article examines the reception of Boscán in Herrera's Anotaciones, paying special attention to the process of belatedness Boscán is subjected to in Herrera's discourse on the sonnet. This process, I argue, shows Herrera's indebtedness to the vocabulary and methods of periodization employed by humanist historiography. The article also explores a few important aspects related to genre and intertextuality in the two sonnets in morte that Boscán wrote in memory of Garcilaso at the end of his petrarchan collection and discusses the reasons why Herrera praised these two poems in his Anotaciones.
\end{abstract}

\section{Keywords}

Boscán; Herrera; Garcilaso de la Vega; periodization; sonnet 
Para el crítico interesado en ir más allá del «superbissimum aurium iudicium» con el que Menéndez Pelayo (1927: 359) despacha de forma sumaria el problema de la recepción de Boscán y su postergación en el canon, las Anotaciones de Herrera constituyen un punto de parada obligado. Aunque el propósito manifiesto de las Anotaciones es el de comentar, interpretar y expurgar el verso de Garcilaso, las opiniones sobre la obra de Boscán que Herrera vierte en su texto marcan en buena medida la respuesta posterior de críticos y lectores al poemario del barcelonés. Así, la opinión que Saavedra Fajardo expresa en 1612 en su República literaria, en la que reclama mayor clemencia para Boscán "por ser extranjero en la lengua» (1967: 49) y desconocer, por tanto, los recursos fónicos y prosódicos del castellano, se hace eco del conocido dictamen herreriano sobre las asperezas y descuidos estilísticos del catalán, disculpables, en su opinión, por «ser estrangero de la lengua en la que publicó sus intentos». ${ }^{1}$ Trescientos años después, la caracterización de Boscán como poeta sólo apto para extranjeros que Menéndez Pelayo hace en el volumen trece de su Antologia de poeta liricos castellanos — «los extranjeros, a quienes podía ofender menos el áspero son de sus versos, se le mostraron siempre más benévolos» (1927: 157) — repite otra vez el veredicto de las Anotaciones y confirma el peso del volumen herreriano en la Rezeptiongeschichte de la poesía del barcelonés.

Este peso o influjo se muestra de forma todavía más clara en la persistencia con la que críticos y editores modernos se han aferrado a esa imagen herreriana de Boscán como poeta lastrado por el pasado cancioneril "en que se crió», ${ }^{2}$ pasado del que el poeta consigue desprenderse sólo ocasionalmente, y que lo aparta, por tanto, de una modernidad plena que para Herrera encarna ya el verso de Garcilaso. Esta imagen profundamente herreriana de Boscán es la que encontramos reproducida, por ejemplo, en el prólogo a una edición de las Obras del barcelonés publicada recientemente por Cátedra, donde Boscán aparece de nuevo envuelto en un «estricto corsé» octosilábico del que sólo puede desembarazarse parcialmente gracias al asesoramiento de Garcilaso, vía única de acceso a toda forma de novedad poética: «Más adelante, aflojado del estricto corsé que se había marcado y ampliadas sus fuentes gracias a los consejos literarios de Garcilaso, van apareciendo asuntos modernos en sus poemas: copias de Petrarca, ecos de Serafino Aquilano y Pontano, detallitos y asunciones del nuevo amor platónico, reinvenciones de Ausías March, influencias de Garcilaso y el inédito interés por mostrar un amor pletórico y correspondido en los sonetos finales, tras el noviazgo y boda con Ana Girón». ${ }^{3}$

El Boscán que la crítica y el público lector heredan de las Anotaciones es pues un poeta de escasas luces y espesas sombras; una figura a caballo entre dos épocas y dos idiomas a la que su propia liminaridad parece pasarle factura,

1. Herrera (2001): 279.

2. Herrera (2001): 279.

3. Clavería (1999): 15. 
tanto desde el punto de vista lingüístico como cronológico. Este último aspecto, el cronológico, merece, creo, especial atención ya que viene ligado a un importante factor en la teoría herreriana del soneto al que rara o ninguna vez se ha prestado atención. Me refiero a la identificación que Herrera establece entre soneto y modernidad, entendiendo por ello la idea de una nueva franja en la historia del occidente europeo caracterizada por el retorno a la cultura clásica y por un deseo firme de ruptura con la bárbara y oscura media aetas que sigue a la caída del imperio romano. Esta idea, propagada desde finales del Cuatrocientos por los historiadores vinculados al movimiento humanista, tiene, como discutiré en la primera parte de esta contribución, un impacto crucial en la formulación que Herrera hace del soneto y en la visión particular de Boscán que nos ofrece en el «discurso» sobre esta estrofa que antecede a su comentario al soneto I de Garcilaso. En este segmento de las Anotaciones, Herrera, como veremos, posterga en el tiempo a Boscán valiéndose del vocabulario desarrollado por la historiografía humanista a la hora de establecer una división clara entre los meliora secula de la «edad presente» y la indocta tenebras del periodo precedente. Esta estrategia, muy marcada en el «discurso» sobre el soneto que precede al grueso de las Anotaciones, queda suspendida, no obstante, en el breve elogio que Herrera dedica a los dos sonetos "en la muerte de Garci Lasso» con los que Boscán cierra el «libro segundo» de sus Obras poéticas. El juicio favorable que estos dos poemas reciben en las Anotaciones invita a un examen detenido de los mismos que dé cuenta de su excepcionalidad en el volumen y que elucide, al mismo tiempo, algunos aspectos hasta ahora ignorados de su textura retórica, genérica e intertextual. A este complicado ejercicio dedicaré la segunda parte de esta contribución, que será necesariamente limitada por razones de espacio.

\section{Boscán en tinieblas: los efectos de la cronología humanista en las Anotaciones}

A pesar de su evidente amplitud temática como «silva de varia erudición», ${ }^{4}$ las Anotaciones de Herrera han sido escasamente estudiadas desde un punto de vista interdisciplinario. La atención que la crítica ha dedicado al volumen se ha enfocado principalmente en la historia literaria y la teoría poética, intentando, en buena parte de los casos, identificar con notable éxito las fuentes que maneja Herrera para articular sus ideas sobre poesía y cómo esas ideas conforman su percepción de Garcilaso, su visión del canon vernáculo y la composición de su propio verso. Este enfoque histórico y literario ha generado un número considerable de estudios y comentarios sobre diversos aspectos teóricos e intertextuales del texto que han soslayado, no obstante, los numerosos puntos de contacto que este mantiene

4. Montero (1997): 98. 
con otras disciplinas. ${ }^{5}$ El ejemplo quizá más conspicuo de este tipo de elisión lo constituye el hecho de que la historia no haya todavía conseguido ocupar un lugar relevante en la tradición exegética sobre las Anotaciones. ${ }^{6}$ La omisión resulta especialmente llamativa si tenemos en cuenta que la carrera de Herrera como hombre de letras comienza en 1572 con un texto histórico, La relación de la Guerra Chipre y suceso de la batalla naval de Lepanto, y que su proyecto más ambicioso, según la semblanza que de él traza Francisco Pacheco en su Libro de verdaderos retratos (1599), era una «istoria general del mundo hasta la edad del emperador Carlos Quinto» ${ }^{7}$ que se ha perdido y que estaba en proceso de redacción cuando las Anotaciones aparecen publicadas en 1580. Ignorar, como se ha hecho, estos importantes datos biográficos y editoriales hace difícil para el lector comprender la presencia en las Anotaciones de pasajes como este, en el que la historia, y no la poesía, ocupa el centro de la atención crítica, puesto que Herrera se expresa más como historiador frustrado que como teórico o crítico literario:

Mas ¿para qué me alargo con tanta demasía en estos exemplos, pues sabemos que no faltaron a España en algún tiempo varones eroicos? ¡Faltaron escritores cuerdos i sabios que los dedicassen con immortal estilo a la eternidad de la memoria! I tuvieron mayor culpa d'esto los príncipes i los reyes de Espańa, que no atendieron a la gloria d'esta generosa nación i no buscaron ombres graves y suficientes para la dificultad i grandeza de la historia; antes escogieron los que les presentava el favor i no sus letras i prudencia. I hasta aora sentimos esta falta con profunda inorancia de las hazañas de los nuestros, porque no ai entre los príncipes quien favoresca a los ombres que saben i pueden tratar verdadera i eloquentemente, con juizio i prudencia, las cosas bien hechas en paz i en guerra (2001: 904).

Si no tenemos en cuenta el perfil de Herrera como historiador nos veremos tentados a ignorar pasajes como este $\mathrm{o}$ a desecharlos simplemente como producto

5. Un recorrido por la bibliografía que Francisco Javier Martínez Ruiz (1997) examina en su artículo-reseña bastará para constatar la predominancia del enfoque histórico literario que señalamos aquí. Esto no significa, desde luego, que la crítica permanezca ajena al carácter enciclopédico e interdisciplinario de las Anotaciones. Como claramente advierte Pedro Ruiz Pérez: «Desde la historia natural a la filosofía del amor, desde la física de la visión a la mitografía, un repertorio de saberes se ordenan a partir del verso de Garcilaso y se ponen al servicio de la propuesta interpretativa y estética de Herrera, demostrando la vitalidad de una cultura más allá de los anaqueles de las librerías y la lectura culturalista» (1997a: 131).

6. Todavía sigue vigente y pendiente de res- puesta, en este sentido, la observación que hiciera Mary Gaylord a comienzos de los setenta con respecto a la vinculación historiográfica de las Anotaciones: "The commentary shows Herrera to have been acquainted with much of the historical, philosophical and literary writing of his age» (1971: 116).

7. Pacheco (1985): 178. Francisco de Medina se refiere también a esta historia general en su prólogo a las Anotaciones: «En aqueste libro [Anotaciones] nos podemos entretener en cuanto sale a la luz la grande i universal istoria que va componiendo, donde se verán eloquentemente contadas las más notables cosas que an sucedido en el mundo, no solamente en Espańa, con la gravedad i copia que mandan las leyes d'esta escritura» (2001: 201). 
del afán enciclopédico de las Anotaciones o de la proverbial tendencia a la digresión de su autor. Si los consideramos, sin embargo, en los lindes de un contexto historiográfico nos daremos cuenta no sólo de la presencia del Herrera historiador en las Anotaciones (el «hasta aora» al que Herrera extiende aquí los problemas de mecenazgo para la historia constituye, obviamente, una forma de llamar la atención sobre su propia labor como historiador), sino también del impacto en el volumen del discurso historiográfico humanista. Encontramos la misma amarga queja de Herrera a propósito del descuido y abandono de la historia por parte de los "príncipes i reyes de España», por ejemplo, en el De historia institutione dialogus (1557) de Sebastián Fox Morcillo, donde se hace a «la negligencia de nuestros príncipes» responsable directa de la escasez de crónicas y relatos sobre «las muchas cosas que nuestros hombres hicieron en los tiempos primeros o en los más recientes» (2000: 266). ${ }^{8}$ Más próximo en el tiempo a las Anotaciones, Ambrosio de Morales se lamenta también en el prólogo al segundo libro de su Corónica de España (1574-86) sobre la falta de una robusta tradición historiográfica en el suelo patrio y culpa de forma implícita a la monarquía española de tal deficiencia al recordar un episodio embarazoso ocurrido en el verano de 1560 durante las bodas entre Felipe II e Isabel de Valois en Toledo:?

(. . .) no teníamos en Espańa tal noticia de nuestras cosas antiguas que sin vergüenza pudiésemos mostrarla delante todos los estrangeros que muchas veces nos dan en rostro con que nunca hemos sido los españoles para hazer una historia de nuestras cosas, ni dar una buena relación de nuestras antigüedades por donde la nuestra y las otras naciones supiesen con certidumbre, y las celebrasen como ellas merecen. Particularmente el año de mil y quinientos y sesenta, quando el Rey nuestro señor venido de Flandes se casó, estando la corte en Toledo como que allí todos los embaxadores de las señorías y potentados de Italia, y todos davan luego en esto, y sentían esta falta como nuestro opprobio, y mostrando mucho deseo de verla suplida y remediada. Dolíame a mi mucho el entender con quanta razón se quexavan y nos zaherían nuestro descuydo (1574: iiiv).

La presencia de este motivo en las Anotaciones, común entre los cronistas e historiadores del Quinientos, indica cuán próximo se encuentra el volumen de

8. Aunque la similitud en tono y contenido entre Herrera y Fox Morcillo refleja solamente la familiaridad del primero con el lenguaje y los motivos de la historiografía humanista, es posible que Herrera tuviera acceso al texto de Fox Morcillo después de la redacción de las Anotaciones a través de Benito Arias Montano. Como Vicente Bécares Botas señala (1999), la biblioteca de Fox Morcillo fue comprada en 1588 en Flandes por Arias Montano. Varios de los volúmenes comprados, y otros procedentes de las prensas flamencas de Plantino (editor del
De historia de Fox en 1557), fueron después distribuidos por Arias a los intelectuales y hombres de letras sevillanos cuando este estableció su residencia en Sevilla y La Peńa de Aracena en la última década de su vida.

9. Cabe notar que la falta de apoyo de la monarquía española a la labor historiográfica continuará hasta bien entrado el siglo xvir. Como constata Elliott (1978: 53), Olivares se refiere específicamente a este problema en una carta enviada Felipe IV en la que señala como una de las faltas más graves de la Corona la desatención a la historia. 
Herrera a los temas y preocupaciones de la historiografía humanista y hasta qué punto esos temas tienen un papel visible en la composición del texto. Ese papel, cierto es, resulta en ocasiones meramente ornamental y revela poco más que un deseo superficial por demostrar erudición, pero en otros casos contribuye de forma significativa al desarrollo de las ideas sobre poesía y géneros poéticos que Herrera expone en sus comentarios a Garcilaso. Buen ejemplo de esto es la asociación entre soneto y modernidad que el sevillano establece en el «discurso» inaugural que acompaña a su glosa explicativa sobre el soneto I de Garcilaso. Dicha asociación se articula sobre los criterios de periodización y el vocabulario específico que desarrolla la historiografía humanista para separar su época de la previa e influye de modo directo en la caracterización que Herrera hace de Boscán como poeta preterido y postergado en el tiempo. Tal caracterización tiene pues bastante que ver, como intentaré enfatizar aquí, con determinados aspectos extraliterarios que conforman la teoría herreriana del soneto y con la vinculación que la obra no historiográfica del sevillano mantiene con la historia, vinculación que ha sido examinada parcialmente en su poesía pero cuyo impacto en las Anotaciones permanece todavía sin explorar. ${ }^{10}$

La mejor manera de analizar la impronta que el discurso historiográfico deja sobre el soneto y sobre la imagen que asimismo se construye de Boscán es fijando nuestra atención por un momento, a modo de preámbulo, en un lugar de las Anotaciones bastante distanciado de estos dos asuntos. Se trata de un pasaje en el que Herrera se detiene a examinar el devenir histórico de Roma para contextualizar la variedad estilística de la elegía como género poético:

I de aquí procede en parte la diversidad de formas del dezir (. . .) I en un mesmo elegíaco se puede considerar esta diferencia, i por esto no se deven juzgar todos por un exemplo ni ser comprehendidos en el rigor de una mesma censura. Porque como después de la felice i gloriosa edad de Augusto perdiesse la poesía parte de su simplicidad i pureza i entrasse después en Italia la bárbara, pero belicosa nación de los godos, i destruyendo los sagrados despojos de la venerada antigüedad, sin perdonar a la memoria de los varones esclarecidos, como si a ellos solos tocara la vengança de todas las gentes sugetas al yugo del Imperio Romano, se mostrassen no menos crueles enemigos de las disciplinas i estudios nobles que de la grandeza i magestad del nombre latino, fue poco a poco oscureciendo i desvaneciéndose en la sombra de la inorancia la eloquencia i la poesía con las demás artes i ciencias que ilustran el ánimo del ombre i lo apartan de la confusión del vulgo, i si quedó alguna pequeña reliquia de erudición, parecía en ella el mesmo trato i corrompido estilo que traxo la gente vencedora (2001: 559).

Si algo queda claro en este pasaje es que poesía e historia no son para Herrera compartimentos estancos, sino vasos comunicantes. Si el contexto histórico

10. Para el impacto de la historia en el verso herreriano, consúltense, entre otros, los trabajos de Woods (1981), Cruz Giráldez (1986) y, más recientemente, Middlebrook (2009: 138-74). 
permite, por un lado, explicar la idiosincrasia estilística de la elegía, los cambios que experimenta la poesía latina sirven también, por otro, para establecer una clara distinción entre dos épocas: la "felice i gloriosa edad de Augusto" y la larga edad de sombras que le sigue. Herrera se vale así de una estrategia de la que hará uso también en su "discurso» sobre el soneto y que resulta especialmente grata, como es sabido, al humanismo: utilizar la poesía como instrumento de segmentación cronológica. Esta estrategia, puesta en práctica por primera vez por los historiadores y hombres de letras del Cuattrocento, obtiene también, no obstante, señaladas manifestaciones en el humanismo hispano de las que es posible que Herrera quisiera hacerse eco. Así, como Emilio Mitre nos recuerda (1999: 78), el erudito sevillano Alfonso García Matamoros (1490-1550) hace directamente responsables a los germanos en su De ratione dicendi de introducir a Occidente en una «larga noche de la barbarie» al haber truncado con su ignorancia la gloriosa tradición poética y literaria romana.

La influencia del humanismo y su práctica historiográfica en el pasaje de las Anotaciones antes citado resultan todavía más evidentes si consideramos, además, el tipo de fractura que Herrera introduce en el mismo. La división que el sevillano establece entre la insigne "edad de Augusto" y la barbarie posterior reproduce, grosso modo, el gesto fundacional de la historiografía humanista, que, como Elena Lombardi observa, surge a partir de la división establecida por Petrarca entre Antigüedad y Medievo en su obra epistolar y poética: «Petrarch, and after him the early Italian humanists, mark the end of the Middle Ages by signaling their beginning - by registering the severance of the continuity between antiquity and the Middle Ages, a distinction foreign to the medieval mind" (2010: 22). La división que Petrarca establece adquiere ya grado de oficialidad a finales del Cuatrocientos en obras como las Decades historiarum ab inclinatione imperii (1483) de Flavio Biondo, en las que la inclusión de vocablos como inclinatio en el título comunican de forma clara la idea de una fractura entre la época imperial y el periodo de decadencia que acompaña a las invasiones germánicas. ${ }^{11}$ Este tipo específico de partición cronológica refleja, según Eric Cochrane (1981: 15), la importancia que las nociones de cambio y discontinuidad adquieren en el nuevo discurso de la historiografía humanista, nociones que resultan completamente ajenas a la práctica historiográfica medieval, en la que, como Eugene Rice y Anthony Grafton observan, se hace constante hincapié en la noción de continuidad y en la idea de un presente eterno que vuelve contemporáneos todos los acontecimientos: «since the medieval historian had believed that his own historical epoch went back to the reign of Augustus (. . .) he regarded the Romans as his contemporaries» (1994: 81). Para el historiador humanista esta

11. Para la influencia fundamental de Biondo en la producción historiográfica posterior, véase el artículo de Hay, que se enfoca en las nociones de declive y resurgimiento en la obra de este historiador. 
concepción del tiempo como una continuidad uniforme e indivisible carece ya totalmente de sentido y, como resultado, la historia queda dividida en edades o periodos, largos segmentos de tiempo acotados por la incidencia de grandes acontecimientos culturales y políticos. ${ }^{12}$ La huella que el impacto de este sistema de periodización deja en la historiografía europea es, como señala Mommsen (1942: 239), decisiva, y su influencia se hace sentir a lo largo y ancho del continente, incluyendo Espańa, donde el sentido de distancia y fractura de época que identifica a los «tiempos modernos» aparece ya reflejado, en opinión de Robert Tate, en el Paralipomenon (1480) del gerundense Joan Margarit i Pau, obra escrita, y no por casualidad, por un autor formado en Italia y familiarizado con los métodos de trabajo del humanismo historiográfico: «First of all he [Margarit i Pau] rejects the medieval historians. He refers to the Toledano [el historiador y arzobispo de Toledo Francisco Jiménez de Rada] as merely a 'tolerable' authority and subsequent writers as an ignorant horde, spreaders of dreams and prophecies (...) These remarks on the Toledano and his followers are among the first, if not the first reflections by a peninsular writer of a change in the critical attitude towards the immediate past that constituted the raison d'être of humanism». ${ }^{13}$

Conviene notar para terminar este pequeño preámbulo, que la introducción del nuevo sistema de periodización histórica que propone el humanismo se articula, en la mayor parte de los casos, a través de un vocabulario estandarizado que no sólo permite establecer marcadas divisiones cronológicas entre épocas, sino también imponer juicios de valor sobre las mismas. De especial importancia en este sentido es el par antitético luz/tiniebla, al que se recurre de forma asidua, bien sea directamente o a través de sus múltiples derivados, para designar respectivamente el esplendor de la antigüedad grecolatina y la decadencia y corrupción de la media aetas que le sigue. Herrera no es ajeno al uso sistemático de esta terminología, como lo demuestra la referencia al «oscureciendo y desvaneciéndose en la sombra» con que explica el declive cultural que tiene lugar en Roma tras la muerte de Augusto en su discurso sobre la elegía. También García Matamoros, al que nos hemos referido antes, se hace eco de este recurso terminológico al describir como «larga noche de la barbarie» la época que inauguran las invasiones germánicas en Europa. El punto de partida para el uso sistemático de este

12. Estas edades o periodos son generalmente tres (Antigüedad, Medievo y Modernidad) y, aunque su origen puede rastrearse ya en la obra de los humanistas del Trecento (Salutati y Filippo Villani, en particular), su uso, como advierte McLaughlin (1988: 141), no se generaliza hasta la centuria siguiente, en la que comienza a estudiarse con detenimiento la evolución de la literatura latina desde la Antigüedad. Conviene aclarar, por otro lado, que la noción de edad o periodo existe ya en la historiografía medieval, en la que con frecuencia se alude a las «seis edades del mundo" establecidas por San Agustín en su De catechizandis rudibus . La existencia de estas edades no implica, sin embargo, un cuestionamiento de la uniformidad del devenir cronológico, para cuya segmentación se emplea el nombre de personajes y acontecimientos bíblicos como los de Adán, Abraham, David, el cautiverio en Babilonia o el nacimiento de Cristo.

13. Tate (1952): 151. 
vocabulario normativo y peyorativo es, como han advertido Mommsen (1942) y otros estudiosos, unos versos del África de Petrarca en los que se contrasta lo lúgubre de los tiempos presentes frente al esplendor clásico, y se expresa un vívido anhelo por regresar al antiguo fulgor grecolatino: ${ }^{14}$

(...) michi degere vitam.

Impositum varia rerum turbante procella.

At tibi fortassis, si-quod mens sperat et optat-

es post me victura diu, meliora supersunt

secula: non omnes veniet Letheus in annos

iste sopor! Poterunt discussis forte tenebris

ad purum priscumque iubar remeare nepotes. (IX, 446-57)

[Mi destino es vivir entre diversas y confusas tormentas. Pero para ti quizá, si, como espero y deseo, vives largo tiempo después de mí, vendrán mejores tiempos. Este sueño del olvido no durará eternamente. Podrá, despejadas acaso las tinieblas, volver a lo puro y prístino nuestra progenie]. ${ }^{15}$

Aunque concebida originalmente como vehículo para denunciar las carencias literarias y culturales de sus contemporáneos, la fórmula de Petrarca se convirtió pronto en moneda de uso común en la historiografía humanista, que la aplicó, como Mommsen ha señalado (1942: 228), de forma laxa y fuera de contexto para asignar a su propia época el lugar que le correspondía dentro del curso de la historia. Así, como resultado de este uso descontextualizado, vocablos como luz, resplandor y brillo, por una parte, y noche, oscuridad y sombra, por otro, fueron incorporados rápidamente a la jerga historiográfica para distinguir no sólo el periodo clásico del medieval, sino también este último del moderno o contemporáneo, que quedó de esta forma definido, según Petrarca había ya adelantado en su poema épico, como una nueva era luminosa e ilustrada que permitiría a los hombres retornar al esplendor grecolatino y dejar atrás el largo, confuso y oscuro medium tempus en el que habían estado sumidos desde la disolución del imperio romano. ${ }^{16}$

En este nuevo y radiante presente moderno es en el que Herrera sitúa el soneto, al que dedica el primero de sus «discursos» o exposiciones teóricas en las Anotaciones. La crítica ha venido leyendo este extenso segmento del texto como

14. Como antecedente de Petrarca Robert Black (1995) señala la literatura medieval eclesiástica, en la que en ocasiones se recurre a este tipo de vocabulario para separar la antigua edad pagana de los clásicos de la nueva edad que inaugura el nacimiento de Cristo.

15. Ofrezco aquí mi propia traducción del pasaje citado del África.

16. Algunos medievalistas han estudiado las implicaciones ideológicas de esta decisión terminológica adoptada por el humanismo dentro del contexto de la teoría postcolonial contemporánea para formular la existencia de un «colonialismo cronológico» que se nutre de la herencia intelectual de Petrarca. Véase a este respecto el estudio que John Dagenais ha publicado en colaboración con Margaret Greer (2000). 
un complejo ejercicio intertextual de erudición retórica y literaria que confirma, entre otras cosas, el conocimiento que Herrera poseía de los tratados clásicos y contemporáneos sobre poética y también su preferencia por la imitación mixta como método de composición literaria. ${ }^{17}$ Junto a su denso y heterogéneo bagaje teórico-literario, el «discurso» de Herrera manifiesta también la familiaridad de su autor con el vocabulario y los métodos de periodización de la historiografía humanista y la influencia de estos en su concepción del soneto y su formulación del canon, especialmente en lo que se refiere a la figura de Boscán. Esto resulta evidente en la sección del «discurso» que Herrera dedica a comparar los logros poéticos de italianos y españoles antes de la irrupción en escena de Garcilaso. Herrera comienza mencionando aquí, tras haber ahondado en las diferencias que separan a lengua italiana de la española, la considerable distancia cronológica (entendido como retraso cultural de España con respecto a Italia) que, en su opinión, existía hasta hace poco entre estas dos naciones, distancia que él mide según el grado de conocimiento y destreza con el soneto mostrado por sus poetas:

Que ayan sido ellos [los italianos] en este género [el soneto] más perfetos i acabados poetas que los nuestros, ninguno lo pone en duda, porque an atendido a ello con más vehemente inclinación i an tenido siempre en grande estimación este exercicio. Pero los españoles, ocupados en las armas con perpetua solicitud hasta acabar de restituir su reino a la religión cristiana, no pudiendo entre aquel tumulto i rigor de hierro acudir a la quietud i sossiego d'estos estudios, quedaron por la mayor parte agenos de su noticia i apena pueden difícilmente ilustrar las tinieblas en que se hallaron por tan largo espacio de ańos (2001: 278).

Desde un punto de vista cronológico, el hecho de que Herrera haga coincidir la falta de familiaridad de los espańoles con el soneto con la larga pugna contra el Islam en la península es ciertamente revelador, ya que enfatiza claramente el papel de esta estrofa como jalón o marca de separación entre dos épocas (Reconquista y post-Reconquista) y como emblema cultural de una nueva edad definida por «la quietud y sossiego d'estos estudios» y no por el "tumulto i rigor» militar del periodo precedente. ${ }^{18} \mathrm{El}$ acceso a esta nueva era, como da a entender el sevillano, le fue concedido primero a los italianos, y esto lo demuestra el conocimiento y pericia de sus poetas con el soneto, factor este que los separa cla-

17. El marco teórico e intertextual del «discurso" ha sido meticulosamente estudiado por Brown (1975), Lázaro Carreter (1980) y Morros (1998: 107-146). El lugar que Herrera asigna al soneto en su clasificación y teorización de los géneros poéticos ha sido discutido, entre otros, por Macrí (1972) y López Bueno (1997: 183-187).

18. Herrera hace caso omiso aquí, obviamente, del propio "tumulto i rigor" que envuelve a su propia época. Como apunta Juan Montero, las Anotaciones se publican «en un momento histórico marcado todavía por los ecos victoriosos de Lepanto y con la anexión de Portugal a la corona de Castilla como contexto inmediato» (1997: 103). A la importancia de este contexto se refiere también Rachel Schmidt al analizar el vocabulario bélico que Herrera utiliza para representar la relación con Italia en el volumen. 
ramente de sus colegas españoles, «agenos» hasta fecha reciente «de su noticia» y condenados, por tanto, a vivir en tinieblas "por tan largo espacio de años». La visión que Herrera tiene del soneto es pues, como este pasaje refleja, la de una estrofa que literalmente marca época y cuyo impacto en la cultura es no sólo estético o retórico, sino también cronológico.

Tal visión está fuertemente condicionada por los métodos de periodización de la historiografía humanista y por el vocabulario desarrollado por esta con el objeto de segmentar el tiempo y estructurar el devenir histórico de acuerdo con sus propios valores. El uso que Herrera hace de la palabra «tinieblas,» rendición directa del tenebras que Petrarca y los primeros humanistas habían adoptado para instaurar y al mismo tiempo estigmatizar la media aetas a la que da principio la caída de Roma, permite apreciar con claridad el impacto que el discurso historiográfico del humanismo tiene en las Anotaciones y el influjo evidente de la cronología humanista en la formulación herreriana del soneto. Este influjo resulta palpable de nuevo en la breve reflexión que Herrera hace sobre la entrada del soneto en España y los primeros escarceos de los poetas españoles con esta estrofa. La reflexión insiste una vez más en el papel del soneto como inaugurador de una nueva época al alabar los Sonetos fechos al italyco modo de Santillana por «la luz que tuvieron en la sombra y confusión de aquel tiempo» y, al mismo tiempo, relega a Boscán a un segundo plano al arrebatarle la primacía cronológica que él mismo se había otorgado en el «libro segundo» de sus Obras poéticas, al señalarse como primer sonetista en castellano:

Mas ya que an entrado en Espańa las buenas letras con el Imperio i an sacudido los nuestros el yugo de la inorancia, aunque la poesía no es tán generalmente onrada i favorecida como en Italia, algunos la siguen con tanta destreza i felicidad que pueden poner justamente invidia i temor a los mesmos autores d'ella. Pero no conocemos la deuda de avella recebido a la edad de Boscán, como piensan algunos, que más antigua es en nuestra lengua, porque el Marqués de Santillana, gran capitán español i fortíssimo cavallero, tentó primero con singular osadía i se arrojó venturosamente en aquel mar no conocido, i bolvió a su nación con los despojos de las riquezas peregrinas. Testimonio d'esto son algunos sonetos suyos dinos de veneración por la grandeza del que los hizo i por la luz que tuvieron en la sombra i confusión de aquel tiempo, uno de los cuales es este $(2001: 278) .{ }^{19}$

Querer leer las palabras de Herrera simplemente como manifestación de un deseo colectivo de translatio studii o como expresión de su rigor y puntualidad como historiador de la literatura al recordar el papel como innovador de Santillana significa limitar en exceso las posibilidades interpretativas de este pasaje

19. Que Herrera inserte a renglón seguido un soneto de Santillana ( $«$ Lexos de vos e cerca de cuidado») en este pasaje habla bien a las claras de la importancia que el sevillano intenta concederle a esta composición del Marqués.
Recordemos que, como Ignacio Navarrete (1994: 137-151) y otros han señalado, esta es precisamente la estrategia de autolegitimación que Herrera utiliza con su propia poesía en las Anotaciones. 
y obviar su interesante dimensión cronológica e historiográfica. El uso que el sevillano hace del contraste entre luz y sombra para significar la trascendencia periodizadora que para él tienen algunos poemas de Santillana no deja lugar a dudas respecto a la estrecha relación entre soneto y modernidad en las Anotaciones y a la deuda que dicha relación guarda con la práctica historiográfica del humanismo. Esta deuda se extiende aquí más allá del uso de un vocabulario específico para demarcar y segregar épocas (luz versus sombra) e incluye la idea de una visión cíclica de la historia que, como Peter Burke ha señalado (1969: 87), resulta común a los historiadores humanistas del Quinientos. Herrera se adhiere claramente a esta interpretación cíclica de la historia al situar la nueva era que inaugura el soneto en un contexto imperial que favorece el estudio y el ejercicio de las buenas letras ( Mas ya que an entrado en España las buenas letras con el Imperio») y definir de este modo los nuevos tiempos como una especie de restauración de «la felice y gloriosa edad de Augusto» que él mismo evoca y enaltece en su discurso sobre la elegía, época en la que, como se recordará, la poesía se practicaba también "con destreza i felicidad» antes de haber sido corrompida y "oscurecida» con la llegada de los bárbaros. ${ }^{20}$ De forma significativa, Herrera desvincula de esta renovatio cíclica que anticipan parcialmente los sonetos de Santillana a Boscán, consiguiendo así restarle protagonismo como introductor de esta estrofa y difuminando asimismo su relación con la nueva edad de las «buenas letras» que se ha desarrollado, pari passu, con el Imperio.

Esta maniobra de postergación y solapamiento cronológico se repite otra vez, aunque en contexto diferente, en el sucinto pero enjundioso examen que Herrera dedica a algunos de los compañeros de generación de Garcilaso en las postrimerías de su "discurso". Herrera enumera en esta breve sección algunas de las razones que, en su opinión, explican el fracaso de Boscán como poeta endecasilábico, refiriéndose al final, de forma explícita, a motivos de índole cronológica:

Boscán, aunque imitó la llaneza de estilo i las mesmas sentencias de Ausías, i se atrevió a traer las joyas de Petrarca en su no bien compuesto vestido, merece mucha más honra de la que le da la censura i el rigor de jueces severos, porque si puede tener desculpa ser estrangero de la lengua en que publicó sus intentos i no exercitado en aquellas disciplinas que le podían abrir el camino para la dificultad i aspereza en que se metía, i que en aquella sazón no avía en la habla común de España a quien escoger por guía segura, no será tan grande la indinación con que lo vituperan queriendo ajustar sus versos i pensamientos, i no reprehenderán tan gravemente la falta suya en la economía i decoro en las mesmas vozes; que no perdonen aquellos descuidos i vizios al tiempo en que él se crió, i a la poca noticia, que entonces parecía de todas estas cosas, de que está rica i abundante la edad presente (2001: 279-280).

Con su referencia "al tiempo en que él se crió» Herrera vuelve a reiterar en estas líneas esa imagen de Boscán como poeta distanciado del presente a la que

20. Remito aquí nuevamente al lector a Herrera (2001: 559). 
había recurrido al hablarnos de los primeros tanteos con el soneto de los poetas españoles. Que el sevillano atribuya los «descuidos i vicios» del verso boscaniano «a la poca noticia que entonces parecía de todas estas cosas de que está rica y abundante la edad presente» resulta, a este respecto, especialmente significativo, ya que idéntica fórmula había sido utilizada cinco años antes por Gonzalo Argote de Molina para referirse a la obra de Juan de Mena en su Discurso sobre la poesía castellana (1575), obra que Argote contextualiza poniéndola en relación con «la poca noticia que en España hauía entonces de todo género de letras» (1926: 45). ${ }^{21}$ Herrera conocía sin duda el texto de Argote de Molina y su intención en las Anotaciones es presentar a Boscán como un poeta alejado de la actualidad poética haciendo uso de la expresión que Argote había utilizado cinco años antes para comentar el verso de Mena en su Discurso. ${ }^{22}$ En términos cronológicos, para Herrera importa poco que la diferencia de edad que separa a Boscán de Garcilaso sea apenas de diez años o que la poesía del segundo no sea más, en realidad, que una creación editorial del primero. La fractura editorial que se establece, en la edición de 1543, entre las obras del barcelonés y las del toledano se convierte en las Anotaciones en línea que marca el comienzo de una modernidad plena que, encarnada ya en Garcilaso, culmina en los meliora secula de la «edad presente». El espíritu de esta nueva edad lo define la «rica i abundante» noticia que en ella hay de todas las disciplinas que contribuyen a la formación eficiente del poeta humanista (gramática, retórica, poética, etc.), disciplinas en las que Boscán no estaba suficientemente "exercitado», por haberse criado, precisamente, in illo tempore, en un espacio cronológico previo al resurgimiento íntegro de los saberes clásicos promovido por el humanismo a través de su programa de estudio y restauración textual. La familiaridad con este programa resulta esencial, como Herrera sugiere, para la práctica eficaz del soneto como estrofa moderna.

Esta cuestión de la modernidad vinculada a la formación humanista, que Herrera apunta aquí a través del ejemplo negativo de Boscán, aparece reiterada en otros lugares de las Anotaciones donde el sevillano alude al elevado grado de dificultad y sofisticación retórica que exige el soneto como forma poética. Así, al comienzo de su «discurso» Herrera se refiere a esta composición como «la más hermosa i de mayor artificio i gracia que tiene la poesía italiana i española» (2001: 265) para añadir más adelante que su estilo es «dificilissimo» (2001:268) y que merece, por tanto, ser tenida «en mayor estimación» (2001:269) que cual-

21. El Discurso de Argote aparece publicado como parte de los preliminares a su edición de El conde Lucanor, uno más de los proyectos editoriales y anticuarios de este bibliófilo, filólogo, historiador y genealogista sevillano. Para la fortuna crítica de Mena en el Discurso y otros textos auriseculares, véase el detallado artículo de Matas Caballero.

22. Colin C. Smith se ha referido ya a la influencia del Discurso de Argote en las Anotaciones de Herrera y ha investigado la relación entre ambos eruditos dentro del círculo humanista de Juan de Mal Lara en la Sevilla del Quinientos. 
quier otra estrofa en la lengua vernácula. ${ }^{23} \mathrm{El}$ tipo de esfuerzo retórico y estilístico al que obliga el soneto requiere pues, sin duda, un conocimiento profundo de «la eloquencia i la poesía con las demás artes i ciencias que ilustran el ánimo del ombre» ${ }^{24}$ que es prerrogativa del poeta humanista moderno y del que Boscán aparece distanciado en las Anotaciones. Esto lo inhabilita para adaptar de forma eficiente «las joyas de Petrarca» al castellano y por tanto para integrarse plenamente en un espacio cronológico nuevo, la modernidad, en el que el esplendor del paradigma grecolatino fulgura de nuevo en el artificioso y exigente género del soneto, aspecto este que Herrera enfatiza, finalmente, al resaltar la capacidad de esta estrofa para aglutinar las diferentes modalidades poéticas antiguas y condensar en sí «todo argumento" poético:

Sirve en lugar de los epigramas i odas griegas i latinas, i responde a las elegías antiguas en algún modo, pero es tan extendida i capaz de todo argumento que recoge en sí sola todo lo que pueden abraçar estas partes de poesía, sin hazer violencia alguna a los precetos i religión del'arte, porque resplandecen en ella con maravillosa claridad i lumbre de figuras i esornaciones poéticas la cultura i propiedad, la festividad i agudeza, la manificencia i espíritu, la dulçura i jocundidad, l’aspereza i vehemencia, la comiseración i afetos, i la eficacia y representación de todas (2001: 266-267).

\section{Resplandores en la sombra: los sonetos «en la muerte de Garcilaso»}

A pesar de estar lejos de constituir, como la crítica ha señalado, una propuesta teórica original, el sistema de correspondencias que Herrera establece entre los géneros poéticos grecolatinos y el soneto contribuye en buena medida a afianzar el estatus único de esta composición como símbolo de una franja histórica nueva que identifica el retorno al pasado clásico como signo de su propia identidad. Ese retorno no implica, conviene subrayarlo, la idea de un parentesco directo entre el soneto y las modalidades poéticas antiguas, como sugiere López Bueno (1997: 187), sino simplemente la posibilidad de una restauración funcional de las mismas («sirve en lugar de», declara Herrera) a través de una composición que, si bien no ligada genealógicamente a ellas, puede, como bien apuntan Pepe y Reyes (2001:65-66), acoger idénticos «argumentos» y desempeñar, por tanto,

23. Herrera hace similares afirmaciones con respecto a la canción en el «discurso» que dedica también a esta estrofa en las Anotaciones: «I como es el más hermoso i venusto género de poema, assí es el más difícil» (2001: 484). La seriedad de esta afirmación ha sido cuestiona$\mathrm{da}$, sin embargo, por la crítica, que considera superficial y poco elaborado el análisis que $\mathrm{He}$ rrera hace de esta estrofa. Véase a este respecto, por ejemplo, el breve comentario en nota (nota 1) que Pepe y Reyes introducen en su edición de las Anotaciones (2001: 447). Resulta también oportuno advertir, por otra parte, que, al carecer de un número fijo de versos, el grado de dificultad de la canción es, de acuerdo con los criterios utilizados por el propio Herrera, necesariamente inferior al del soneto: «el soneto, que tanta semejança tiene i conformidad con el epigrama (. . .) tanto es más difícil, por estar encerrado en un perpetuo i pequeńo espacio» (268).

24. Herrera (2001): 559. 
un papel poético equivalente. La postura de Herrera es muy clara a este respecto: el soneto "sirve en lugar de los epigramas i odas griegas i latinas," pero no guarda con estas estrofas un vínculo genético. El examen de la fuente a la que Herrera recurre en este pasaje de las Anotaciones, el Trattato di comporre in versi nella lingua italiana (1553) de Girolamo Ruscelli, refuerza claramente esta opinión, ya que, como señalan Pepe y Reyes, la idea de una relación funcional y no genealógica entre el soneto y las estrofas clásicas aparece diáfanamente expresada por Ruscelli: «la frase herreriana está tomada en vilo de Ruscelli, quien afirma Sono i sonetti fatti propriamente per usar alla guisa degli Epigrammi, dell'Ode l Latine Greche» (2001: 66). La incapacidad y falta de preparación que Herrera ve en Boscán para practicar con destreza una composición poética tan fértil y polivalente como el soneto constituye en este sentido una manifestación clara de su postergación cronológica y del carácter premoderno de su poesía. Tal valoración queda, sin embargo, en suspenso en el extenso preámbulo biográfico y encomiástico con que Herrera evoca la figura de Garcilaso al frente de las Anotaciones, segmento que recoge, además de una «vida» del poeta, múltiples composiciones en latín, italiano y castellano en loor del vate toledano. La mención que en este preámbulo se hace a los dos sonetos «en la muerte de Garci Lasso» que Boscán escribe en el tramo final de su cancionero petrarquista contrasta marcadamente con la opinión sobre el poeta barcelonés que aparece expresada en el «discurso» sobre el soneto y otorga por ello a estos dos poemas un grado de excepcionalidad similar al que Herrera atribuye a algunos sonetos de Santillana en el «discurso». Dicha mención llama la atención, además, por la capacidad que Herrera atribuye a estas dos composiciones para alterar radicalmente la posición que él mismo asigna a Boscán en el canon poético del Quinientos:

En nuestra lengua escrivió en alabança de Garci Lasso su gran amigo Juan Boscán (. ..) él mismo compuso dos sonetos en la muerte de Garci Lasso tales que si tuvieran sus obras muchos semejantes a ellos, por ventura merecieran mejor lugar. No los refiero aquí por estar impressos i ser comunes a todos (2001: 215).

Para el lector interesado en rastrear las opiniones de Herrera sobre modalidades estróficas y predecesores poéticos, la necesidad de un análisis detallado de estos dos sonetos y de lo que esta afirmación significa en el contexto de la visión herreriana sobre género y canon es, creo, inevitable. ¿Qué tienen estos dos sonetos que permiten a Herrera señalarlos como modelos poéticos y asignarles un lugar aparte dentro de la obra de Boscán? Esta es la pregunta que intentaré responder en la segunda parte de esta contribución, en la que pretendo, por un lado, reflexionar sobre la excepcionalidad de estas dos composiciones desde una perspectiva genérica, intertextual y retórica y, por otro, ofrecer algunas vías nuevas de lectura que amplíen lo poco que la crítica ha dicho hasta la fecha sobre estos dos poemas. Aunque mi atención se centra principalmente en el primero de ellos (el CXXVIII, siguiendo la numeración original de Boscán), el análisis que ofrezco intenta también elucidar aspectos relevantes sobre el segundo (el 
CXXIX), poema que, en opinión de Antonio Armisén, «merece ser incluido en cualquier antología, siquiera breve, de la elegía renacentista» (1982: 82).

La filiación elegíaca que Armisén señala para el segundo de estos sonetos bien puede servirnos para iniciar el comentario sobre estos dos poemas. Aunque se trata en ambos casos de sonetos in morte que celebran la figura y el renombre de Garcilaso, su acercamiento al fenómeno de la muerte es muy distinto, expresando en cada caso el tipo de perspectiva que Alistair Fowler asocia a las modalidades divergentes del epitafio y la elegía: «Epitaphs are normally about the deeeds and qualities of a particular person and their claim on our attention; funeral elegies are about the thoughts and feelings of those who mourn» (1982: 88) ${ }^{25}$ La proximidad del primer soneto al punto de vista informativo y descriptivo del epitafio queda puesta de manifiesto en el aserto con el que Boscán resume el recorrido vital de Garcilaso en los dos últimos versos: «tus trabajos hicieron larga istoria, / y cúpote, tras esto, corta vida». Este díptico comunica de forma sucinta y casi factual el propósito esencial del poema, que no es otro que el de presentar a Garcilaso como un héroe joven y de existencia efímera, cualidad esta que justifica el extenso símil de inspiración clásica sobre el que Boscán construye el resto del poema:
El hijo de Peleo, que celebrado tanto d'Homero fue con alta lira, con su madre su mal llora y sospira, la suerte lamentando de su'stado.
Que sobre havelle corta vida dado, pase tan adelante la su ira, que doquier que'l rebuelva, si se mira, se vea de trabajos rodeado.
Si la fortuna d'un tal hombre's gloria con gloria quedarás tú, Garcilaso, pues, con la dél, tu gloria va medida.
Tu esfuerço nunca fue flaco ni laso, tus trabajos hicieron larga istoria, y cúpote, tras esto, corta vida.

Si el tono expositivo y escasamente emocional revela la estrecha vinculación de este soneto con el epitafio, lo mismo puede decirse del uso dominante

25. La distinción entre ambos géneros y el tipo de perspectiva que típicamente representan tiene que ver también, obviamente, con la extensión de los mismos. El epitafio, inscripción grabada o pensada para ser grabada sobre una tumba, carece del espacio del que goza la elegía, concebida desde el principio, como señala Friedländer, como "canto fúnebre» más o menos extenso: "The lengthy debate on the origin of the elegy has sometimes veiled rather tan emphasized the obvious fact that as early as the fifth century the word elegos in lyrical passages of Euripides and Aristophanes invariably means a song of mourning» (1948: 65). 
del símil, extendido nada menos que a lo largo de once versos, y de la elección de Aquiles como terminus a quo para la comparación con Garcilaso. Como O. B. Hardison observa, el símil es uno de los recursos retóricos habituales en la poesía funeraria, siendo frecuente en los poemas de este tipo (epitafios y elegías mayormente) la analogía entre el difunto y los héroes de la antigüedad clásica: «Expressions of inadequacy and comparisons are the most frequent of these (...) the poet compares his subject to parallel cases in antiquity and concludes in each instance that his own subject surpasses the historical example» (1962: 116). Aunque Boscán no presenta a Garcilaso como un héroe superior a Aquiles, la comparación entre ambos obedece claramente a las convenciones que rigen el discurso del epitafio como subespecie funeraria. La caracterización, además, del toledano como héroe de «larga istoria» y "corta vida» se hace eco claramente del ökúmoros perì pántōn («de sino breve más que ninguno») ${ }^{26}$ con el que Tetis se refiere a su hijo en el lacrimoso diálogo que mantiene con él al borde del mar al comienzo del poema homérico, escena que Boscán evoca en su soneto al describir al héroe griego llorando y lamentando con su madre "la suerte de su'stado». ${ }^{27}$ La presencia de epítetos y fórmulas épicas como esta resultan frecuentes en el epitafio, como Scodel señala, que recurre a ellas para otorgar un perfil homérico al difunto y garantizarle, de esta forma, fama imperecedera: «Epitaphs often resorted, for example, to epic formulae in an effort to link the dead to Homeric heroes and their undying fame» (1991: 3). Este acomodamiento a los procederes retóricos habituales del epitafio que exuda el soneto de Boscán habría de resultar sin duda grato a un crítico como Herrera, tan preocupado, como Ángel Estévez Molinero ha señalado (1997: 138-139), por el aptum o la adecuación del lenguaje poético a las convenciones propias de cada género poético.

Más importante que este respecto habría de ser el carácter ejemplar que el poema del barcelonés exhibe en relación a la teoría de base epigramática que Herrera utiliza para dar cuenta de la singularidad estructural del soneto en las Anotaciones. Esta teoría, inspirada sobre todo, como la crítica ha observado, en el Comento sopra alcuni dei suoi sonetti de Lorenzo de'Medici, concibe la dispositio de esta estrofa como una suerte de amplificatio que, si bien limitada a "un perpetuo i pequeńo espacio, ${ }^{28}$ desarrolla a lo largo de catorce versos el contenido de un núcleo sentencioso en el que se cifra el «verdadero sugeto i materia» del poema. ${ }^{29} \mathrm{El}$ soneto se resuelve, bajo esta óptica, en una especie de epigrama dilatado en el que el núcleo y el cuerpo del poema se fusionan de tal manera que producen la apariencia de un todo orgánico y espontáneo:

26. Ilíada I, 416.

27. Para la escena completa del diálogo entre Aquiles y Tetis, véase Ilíada I, 352-427.

28. Herrera (2001): 268.
29. Para la conexión que Herrera establece entre el soneto y el epigrama a través del Comento de Lorenzo de' Medici, véanse los trabajos de Brown, Lázaro Carreter y Morros (1998: 107-146). 
I por esta causa su verdadero sugeto i materia deve ser principalmente alguna sentencia ingeniosa i aguda, o grave, i que meresca bien ocupar aquel lugar todo; descrita de suerte que paresca propia i nacida en aquella parte, huyendo la oscuridad i dureza, mas de suerte que no decienda a tanta facilidad que pierda los números i la dinidad conveniente (2001: 267).

El soneto CXXVIII de Boscán se ajusta ejemplarmente a esta estructura ya que expande a través de un símil prolongado un núcleo temático que se concentra, como ya apuntamos, al final del poema. La ubicación postrera de este núcleo hace que su presencia pase prácticamente inadvertida al lector, que la siente por ello como "propia i nacida en aquella parte» y no como un elemento extraño o desligado del cuerpo del poema. Esta capacidad para integrar y expandir el núcleo epigramático convierte al soneto de Boscán en un precedente insoslayable del soneto-epitafio del siglo XVII, subespecie poética abundantísima en la centuria barroca y que, como Ángel Estévez Molinero ha señalado, recoge "la tradición del epigrama en un gradual proceso de fusión/confusión con éste» (1996: 286). ${ }^{30}$

A esta peculiaridad estructural, tan afín a lo que Herrera declara en sus Anotaciones con respecto a la disposición interna del soneto, se le une otra que también habría sido sin duda del gusto del sevillano: la presencia de una encabalgamiento al comienzo mismo del poema: «El hijo de Peleo, que celebrado / tanto d'Homero fue con alta lira». El detalle no resulta baladí, ya que Herrera, siguiendo, como Morros señala (1997: 67-68), la doctrina de Ruscelli y de Lorenzo de' Medici, dedica un extenso párrafo de su discurso sobre el soneto a exaltar el impacto positivo (hermosura, variedad y grandeza) que tal estrategia produce en el poema y a rebatir la postura de aquellos que censuran la fractura de la estrofa "en el primer verso de los cuarteles», usando como ejemplo el soneto I de Garcilaso, "Quien me dixera, cuando en las pasadas / horas»:

No dexaré de traer esta adversión, pues se ofrece lugar para ello, que cortar el verso en el soneto, como

Quién me dixera, cuando en las pasadas

oras

no es vicio sino virtud, i uno de los caminos principales para alcançar l'alteza i hermosura del estilo, como en el eroico latino, que romper el verso es grandeza del modo del dezir. Refiero esto porque se persuaden algunos que nunca dizen mejor que cuando siempre acavan la sentencia con la rima. I oso afirmar que ninguna mayor falta se puede casi hallar en el soneto que terminar los versos d'este modo (. . .) Quieren algunos de los que siguen esta osservación que en el primer verso de los cuarteles i de los tercetos no tenga lugar esta incisión, que la juzgan por vicio indino

30. Estévez Molinero sitúa el origen de esta modalidad poética barroca en el soneto XVI de Garcilaso, «No las francesas armas odiosas».
Creo que los sonetos in morte de Boscán deben también ocupar un lugar central en la genealogía de esta subespecie funeraria. 
de perdonar; i son ellos los que no merecen disculpa en esto, porque antes se alcança hermosura i variedad i grandeza. I d'esta suerte lo vemos en todos los que an escrito con más arte i cuidado (2001: 269-270).

Dada la atención especial que Herrera presta a los efectos del encabalgamiento y, en general, a todos los aspectos relacionados con la elocutio en las Anotaciones, resulta más que concebible que la brecha morfosintáctica con la que Boscán abre su soneto no pasase desapercibida para el sevillano.

Tal vez esta atención minuciosa a los detalles formales del poema hiciese también que le resultase llamativa la compleja trama intertextual que el barcelonés urde en su soneto. Boscán, como ya hemos notado, combina la analogía entre Garcilaso y Aquiles con referencias textuales directas a la Ilíada, referencias que van desde la sencilla y manida perífrasis del inicio («El hijo de Peleo») a ecos de escenas (el llanto de Tetis y Aquiles en la playa) y epítetos (el ökúmoros peri pántōncon el que la diosa se dirige a su hijo) que quizá fueran menos evidentes para el lector de la edición de 1543. Estas referencias se combinan en el poema además con otras que no debieron pasar inadvertidas a un lector erudito del calibre de Herrera. Tal es el caso, por ejemplo, del soneto CLXXXVII de las Rime de Petrarca, en el que se alude, como ya hiciera Cicerón en su Pro Archia ${ }^{31}$ a la fama conferida a Aquiles por parte de Homero, y de Il Cortegiano, donde el personaje de Bembo se refiere asimismo al estatus envidiable del héroe griego por haber conseguido "che le cose sue fossero celebrate da Omero» (I, 7, 39). El eco de estas fuentes es fácilmente reconocible en los versos que inauguran el soneto de Boscán, en los que se recuerda igualmente que Aquiles «celebrado / tanto d'Homero fue con alta lira» (1-2). Esta peculiar convergencia de subtextos habría sido sin duda del agrado de Herrera, como demuestra su recomendación de mezclar «los mejores antiguos» con los italianos para alcanzar fama poética y elevar la lengua vernácula en su «discurso» sobre el soneto:

Yo, si desseara nombre en estos estudios, por no ver envegecida i muerta en pocos días la gloria, que piensan alcançar eterna los nuestros, no pusiera cuidado en ser imitador suyo [de Petrarca], sino endereçara el camino en seguimiento de los mejores antiguos, i juntando en una mescla a éstos con los italianos, hiziera mi lengua copiosa i rica de aquellos admirables despojos, i osara pensar que, con diligencia i cuidado, pudiera arribar a donde nunca llegarán los que no llevan este paso (2001: 273).

La «mescla» de Homero con Petrarca y Castiglione que Boscán pone en práctica en su soneto ejemplifica en buena medida el tipo de estrategia imitativa que Herrera recomienda a sus contemporáneos en las Anotaciones. Este modelo mixto de imitación tiene sin embargo en el soneto de Boscán un horizonte más

31. Véanse a este respecto Pro Archia IX, 24 y Rime CLXXXVII, 1-4. 
amplio que incluye composiciones de la tradición vernácula en las que Herrera probablemente no reparó, y que tienen, en mi opinión, una importancia capital para comprender el verdadero alcance de la dimensión intertextual del poema. Se trata de dos composiciones del propio Boscán con las que el soneto «en muerte» de Garcilaso dialoga a través del gesto autocontemplativo con el que se describe a Aquiles en los versos siete y ocho del mismo: «que doquier que'l rebuelva, si se mira, / se vea de trabajos rodeado». Esta pose autorreflexiva constituye un adendo de Boscán a la fuente homérica, donde Aquiles, a pesar de su cercanía al agua, nunca se autocontempla, y su presencia en el soneto pone a este en contacto con los dos poemas que le preceden en el «libro segundo,» los sonetos CXXVI y CXXVII, en los que el yo lírico se presenta mirándose y contemplándose «entre todos» para celebrar la curación de su dolencia y su salida de la prisión donde Amor lo tenía «embuelto»:

Sé que es así, no sé como s'ha hecho que ahora, libre, entre todos me contemplo, de la fuerte prisión do fui embuelto. (CXXVI, 9-11)

Bolví luego a mirarme y vime sano

y caminé sin rastro de dolencia por las cuestas así como en lo llano. (CXXVII, 9-11)

El contraste entre el Aquiles del soneto a Garcilaso y el yo lírico de estos dos poemas es evidente: mientras que el primero llora su suerte al verse «de trabajos rodeado,» el segundo la celebra al verse libre de toda carga indeseable. Este contraste revela en último término un deseo por subrayar la distancia que separa a Boscán como protagonista de su poemario, del propio Garcilaso, ya que este, como Aquiles, es presentado en el soneto CXXVIII como víctima de perennes «trabajos» que, si bien aumentan y engrandecen su "historia,» menguan y aniquilan proporcionalmente su vida: «tus trabajos hizieron larga historia / y cúpote, tras esto, corta vida» (13-14). El Garcilaso que Boscán evoca para solemnizar su muerte es pues, como «el hijo de Peleo,» un individuo acosado por trabajos $y$, como tal, en franco contraste con el sujeto agraciado y perplejo que, libre por intervención divina de toda penuria, Boscán celebra en el tramo final de su «libro segundo». El vínculo intertextual que el soneto CXXVIII «en muerte» de Garcilaso mantiene con otros poemas boscanianos reafirma así, de esta manera, la trayectoria y el mensaje salvífico y redentorista que constituyen la novedad misma del cancionero del barcelonés y que lo distinguen de su modelo toscano.

A esta singular función del poema como vehículo de contraste y autoafirmación poética se le une otra de carácter social que, como Scodel señala, es intrínseca a la modalidad del epitafio: «the poetic epitaph, a poem inscribed or purporting to be inscribed upon a tomb, participates in the social and therefore historical construction of the dead» (1991: 1). Esta participación del epitafio en la construcción social de la imagen del difunto aparece directamente 
vinculada en el soneto de Boscán a la fuente griega y, de nuevo, al personaje de Aquiles, ya que lo que el poema celebra es la gloria imperecedera o kléos $(x \lambda \hat{\varepsilon} \mathbf{0} \varsigma)$ de Garcilaso, gloria que en la tradición homérica aparece estrechamente ligada a la actividad militar y que exige la muerte prematura del guerrero en el campo de batalla. ${ }^{32}$ La comparación que Boscán establece a lo largo y ancho de su poema entre Aquiles y Garcilaso sitúa claramente la gloria del segundo en este contexto homérico, convirtiendo así al toledano en un icono militar afín a los intereses ideológicos del imperio Habsburgo. Esta imagen, sin embargo, carece de resonancias sólidas en la poesía de Garcilaso, en la que, como señala Arredondo, «se da la paradoja de que, siendo su autor un militar (. . .) apenas hallamos eco de fervor guerrero» (2003: 265). De hecho, como subraya Morros, «a diferencia de otros poetas de su generación, Garcilaso no se prodiga en demasiados homenajes y elogios al oficio al que dedicó toda su vida y que se la arrebató: el de soldado. Más bien se lamenta de haber tenido que ejercerlo (...) porque su práctica a menudo le separó de sus seres más queridos, ya sean amantes, hijo o esposa» (2003: 227). La imagen que Garcilaso cultiva de sí mismo en su verso tiene pues poco que ver con el kléos del guerrero homérico y más, como insinúa Morros, con esa añoranza y deseo de retorno a la patria y al hogar o nóstos (vóotos) ${ }^{33}$ a los que Aquiles renuncia al acudir a Troya y a los que la Ilíada alude en ocasiones a través del propio héroe ${ }^{34}$ y también, como comenta Wofford, al evocar la vida pasada de los contendientes o al describir los objetos que portan: "The Iliad also includes, however, a variety of scenes and images that are set apart from the battle and appear to evoke the very nóstos that Achilles will lose by staying at Troy: in epic similes, digresssions on the warrior's past lives, and in descriptions of certain artifacts, for example, the poem appears to represent an alternative to war» (1992: 5). Ese nóstos o regreso al hogar con el que Garcilaso se identifica debió haber estado muy presente en la mente de Boscán a la hora de redactar su soneto, ya que en la "Elegía II» el toledano hace referencia explícita a este concepto en relación, precisamente, a la situación privilegiada de su amigo, al que imagina en la patria, en compañía de su mujer y contemplando «la deleitosa playa»:

Tú, que en la patria, entre quien bien te quiere,

la deleitosa playa estás mirando

32. Para el kléos homérico y sus implicaciones culturales y literarias, véase muy especialmente Nagy (1979: 26-41) y Finkelberg (2007).

33. Para el significado de nóstos y su oposición al concepto de kléos en el poema homérico, véase Nagy (1979: 29).

34. Así por ejemplo en Ilíada IX, 410-416: «Mi madre, Tetis, la diosa de argénteos pies, asegura que a mí / dobles Parcas me van llevando al término que es la muerte: / si sigo aquí luchando en torno de la ciudad de los troyanos, / se acabó para mí el regreso, pero tendré gloria inconsumible; / en cambio, si llego a mi casa, a mi tierra patria, / se acabó para mí la noble gloria, pero mi vida será duradera / y no la alcanzaría nada pronto el término de la muerte». 
y oyendo el son del mar que en ella hiere,

y sin impedimento contemplando

la misma a quien tú vas eterna fama

en tus vivos escritos procurando,

alégrate, que más hermosa llama

que aquella que el troyano encendimiento

pudo causar el corazón te inflama. (148-149)

Imaginar a Boscán en la patria y acompañado de quien bien lo quiere es para Garcilaso una forma de imaginarse a sí mismo materializando ese nóstos que aparece evocado y añorado con frecuencia en su poesía. Esa constante añoranza aleja al toledano del Aquiles de la Ilíada y lo sitúa más cerca del Aquiles de la Odisea, que preferiría, como confiesa ante Ulises en el Hades (XI, 489-494), estar vivo y ser el más humilde de los siervos que gozar de fama eterna como muerto. Este otro Aquiles de la Odisea, como comenta Nagy, «would trade his kléos for a nóstos" (1979: 35), problematizando de esta forma su estatus como héroe al anular con sus palabras el valor que él mismo concede a la gloria en el canto IX de la Ilíada: «Se acabó para mí el regreso (nóstos), pero tendré gloria inconsumible (kléos)» (413). Semejante problemática existe también, como Arredondo y Morros señalan, en la poesía de Garcilaso, en la que el servicio militar y la gloria que de él se deriva aparecen con frecuencia cuestionados por el anhelo familiar y doméstico que a menudo descubrimos en su verso. Tal anhelo, sin embargo, aparece obviado y silenciado en el soneto de Boscán, cuyo objetivo es el de construir una imagen sin fisuras del toledano en la que aparezcan reflejados exclusivamente los valores marciales del imperio. El poema pretende de esta forma, en consonancia con la función social del epitafio, fabricar una estampa del difunto que perpetúe el orden social y soslaye los factores que lo ponen en peligro.

El tema de la fama, que Boscán desarrolla en el soneto CXXVIII a través de la analogía con Aquiles y la alusión al kléos homérico, ocupa también un lugar prominente en el otro soneto que el barcelonés escribe "en muerte» de Garcilaso, el CXXIX. Este soneto, sin embargo, contempla la inmortalidad desde una perspectiva distinta y complementaria a la del poema precedente al añadir a la noción pagana y horizontal de fama (el renombre alcanzado en la tierra por los mortales a través de la historia) el concepto cristiano y vertical de gloria (el favor del que gozan los elegidos por Dios en el cielo de forma eterna). El Garcilaso que este poema nos presenta no es ya, por tanto, un individuo al que sus muchos «trabajos» han garantizado una «larga historia» entre los hombres, sino un vir bonus al que su trayectoria moral ha permitido subir a los cielos y abandonar la mortal «baxeza» en la que Boscán se encuentra y desde la que escribe a su amigo. Desde un punto de vista genérico, este segundo soneto complementa también al primero al centrarse no tanto en las cualidades o los detalles de la vida del difunto, sino en los sentimientos de los que lamentan su muerte (Boscán en este caso) y situarse de esta forma, siguiendo otra vez la tipología establecida por Fowler, más cerca de la elegía que del epitafio: 
Garcilaso que al bien siempre aspiraste y siempre con tal fuerça le seguiste, que a pocos pasos que tras él corriste, en todo enteramente l'alcançaste,

dime: ¿por qué tras ti no me llevaste cuando desta mortal tierra partiste?, ¿por qué, al subir a lo alto que subiste, acá en esta baxeza me dexaste?

Bien pienso yo que si poder tuvieras de mudar algo lo que'stá ordenado, en tal caso de mí no te olvidaras:

que, o quisieras onrarme con tu lado, o a lo menos de mí te despidieras;

o, si esto no, después por mí tornaras.

La variedad de subtextos a los que Boscán acude para armar su soneto habría de nuevo complacido, como en el caso del soneto previo, a Herrera. Antonio Armisén se ha referido ya a la importancia que el tema de la ascensión tiene en este y otros poemas que cierran el «libro segundo,» en los que el amante se presenta alternativamente elevado por el casto Amor a «'alto monte d'Olympo» (CXXV, 1) o llevando «para'l cielo / con el verde laurel la blanca palma» (CXVI, 13-14). Armisén apunta también como posible fuente de este soneto al cuarto de Garcilaso, en el que el amante contempla la posibilidad de una visita post-mortem a la amada: «muerte, prisión no pueden, ni embaraços, / quitarme de yr a veros como quiera, / desnudo 'spiritu o hombre en carne y hueso" (12-14). A estos textos contemporáneos hay que sumarle otros, no obstante, que ejemplifican esa fusión de antiguos e italianos tan estimada por Herrera. Parte integrante de esa «mescla» ideal a la que alude el sevillano es, en mi opinión, el soneto CCLXXXVII de Petrarca, dirigido también a un amigo y poeta difunto, el florentino Senuccio del Bene, cuya elevación a los cielos es explícitamente evocada en el primer cuarteto por el amante de Laura:

Senuccio mio, benche doglioso et solo m'abbi lasciato, i' pur mi riconforto, perché del corpo ov'eri preso et morto alteramente se' levato a volo.

Or vedi insieme l'un et l'altro polo, le stelle vaghe et lor viaggio torto, et vedi il veder nostro quanto è corto; onde col tuo gioir tempro'l mio duolo.

Ma ben ti prego che'n la terza spera Guitton saluti, et messer Cino, et Dante, Franceschin nostro et tutta quella schiera. 
A la mia donna puoi ben dire in quante

lagrime io vivo et son fatt'una fera,

membrando il suo bel viso et l'opre sante.

La actitud hacia la muerte expresada en este poema es marcadamente diferente a la adoptada por Boscán. El abandono de la prisión mortal y la liberación final del espíritu de Senuccio compensan a Petrarca del dolor y la tristeza que causan la muerte del amigo ("col tuo gioir tempro'l mio duolo»), aspecto este que no tiene cabida en el poema de Boscán. No hay tampoco en este soneto, como la hay en el de Boscán, una exhortación al difunto para que descienda o regrese a esta «mortal tierra» y se despida del amigo o se lo lleve con él. Senuccio es simplemente un intermediario al que Petrarca intenta utilizar para comunicarse con sus predecesores poéticos y con la difunta Laura, cuyo rostro y obras santas el poeta no puede olvidar. Sin embargo, la presencia del nombre del amigo al frente del soneto y el uso del diálogo para comunicarse con él deja pocas dudas con respecto a la influencia del toscano en el poema del barcelonés, influencia que el estatus mismo de Senuccio como amigo y poeta debió facilitar considerablemente. ${ }^{35}$

Pocas dudas deja también el trasfondo clásico de la invocación con la que Boscán exhorta a Garcilaso en el segundo cuarteto de su soneto: «ipor qué tras ti no me llevaste / cuando desta mortal tierra partiste?, / ¿por qué, al subir a lo alto que subiste, / acá en esta baxeza me dexaste?» (5-8). El contexto y la formulación misma de las preguntas que Boscán dirige al toledano guardan un claro eco del diálogo que Escipión Emiliano mantiene con su progenitor, Lucio Emilio Paulo, en la República de Cicerón, diálogo en el que el hijo lamenta la muerte del padre y expresa igualmente un deseo ferviente por abandonar esta mortal «baxeza» $y$ reunirse con sus antepasados: «Quaeso, inquam, pater sanctissime atque optime, quoniam haec est vita, ut Africanum audio dicere, quid moror in terris? Quin huc ad vos venire propero?» (VI, xv) [¡jOh tú, el más venerado y mejor de los padres! Puesto que esta es la vida, según he oído decir a Africano, ¿por qué permanezco en la tierra? ¿Por qué no me apresuro a abandonarla para estar con vosotros?]. ${ }^{36} \mathrm{El}$ hecho de que este pasaje específico pertenezca al conocido "Somnium scipionis,» contenido en el libro sexto de la República, hace bastante plausible que Boscán se valiese de él y lo usase como fuente en su soneto. El «Somnium,» como es sabido, alcanzó, gracias al comentario que de él hizo Macrobio, un grado de popularidad y difusión en el Renacimiento que nunca tuvo el resto del volumen ciceronia-

35. La presencia del nombre del difunto en el poema, tanto en Boscán como en Petrarca, está sin duda relacionada con el uso que ambos sonetos hacen de uno de los esquemas retóricos más comunes en la lírica funeraria, en la que es habitual interpelar al difunto a la vez que se entona su panegírico. Véase a este respecto Pérez Bowie (1993).

36. Me valgo aquí de la traducción que Rafal Pérez Delgado hace del texto ciceroniano en su edición para Aguilar. Para el texto latino utilizo la edición inglesa de Heinemann. 
no (perdido hasta 1820) y su huella es fácilmente rastreable en otros poemas del barcelonés, como por ejemplo la célebre epístola que escribe a Diego Hurtado de Mendoza, donde la vista que el alma goza en compañía de Dios «desde lo alto» se inspira en las ideas filosófico-cosmológicas divulgadas en el «Somnium». ${ }^{37}$

Sin embargo, resulta necesario remarcar que, tanto en el «Senuccio mio» de Petrarca como en el «Somnium», el contacto con los muertos se resume en un «ad vos venire» que no contempla la posibilidad de ese retorno del amigo muerto que se anhela y con el que se especula en el soneto de Boscán: «(. . .) que si poder tuvieras / de mudar algo lo quesstá ordenado (. . .) / después por mí tornaras» (914). Este detalle nos obliga a extender la mirada más allá de los subtextos clásicos e italianos para identificar otras posibles fuentes del soneto. De entre ellas me gustaría destacar aquí, ya para concluir, el episodio bíblico del primer capítulo de los Hechos de los Apóstoles, donde se narra cómo los discípulos, después de haber comido con Cristo, asisten anonadados a su ascenso en una nube a los cielos. Aunque el impacto de este episodio en el poema de Boscán es imperceptible en la faceta estrictamente textual, la huella figurativa de este pasaje no carece de relevancia, ya que en él se hace clara referencia, como en el soneto del barcelonés, al regreso de un difunto que, como sucede con Garcilaso, goza de un estatus dual como amigo y maestro para los que contemplan su arrebato «d'esta mortal tierra»:

Diciendo esto, fue arrebatado a vista de ellos, y una nube le sustrajo a sus ojos. Mientras estaban mirando al cielo, fija la vista en Él, que se iba, dos varones con hábitos blancos se les pusieron delante y les dijeron: 'Hombres de Galilea, ¿qué estáis mirando al cielo? Ese Jesús que ha sido arrebatado de entre vosotros al cielo, vendrá como le habéis visto ir al cielo. (9-11).

Desde la perspectiva doctrinal, la diferencia entre este Jesús que se aparece, almuerza y abandona a los discípulos y el Garcilaso que Boscán invoca en su soneto no puede ser más clara. Mientras que el primero prueba con su visita, y promete después a través de los dos varones de blanco, que puede regresar de los muertos, el segundo no tiene la misma capacidad para «mudar» «lo que'stá ordenado" y su retorno se presenta simplemente como un anhelo o una hipótesis: «si poder tuvieras». Esta diferencia doctrinal no anula, sin embargo, el tipo de analogía contextual y figurativa que Boscán traza con el personaje de Cristo, analogía que el barcelonés utiliza en otros poemas para autorizar la voz y la experiencia del yo lírico del «libro segundo ${ }^{38}$ y que aquí emplea para magnificar el estatus del amigo muerto y complementar con un halo trascendental y cuasi religioso la estampa heroica del toledano desplegada en el soneto previo. Tal ana-

37. Para la influencia del «Somnium» en la «Epístola» de Boscán véase De Armas (1992: 861-63), que identifica este poema como fuente de referencia para Calderón en El pintor de su deshonra.

38. Para la presencia y uso de imágenes cristomórficas en el «libro segundo», véase Lorenzo (2001). 
logía se ve reforzada, además, por el tipo de recursos retóricos en los que Boscán se apoya para entablar el diálogo con Garcilaso (apóstrofe e interrogatio), recursos que forman parte del repertorio habitual de figuras utilizado en la literatura exegética y la oratoria sagrada para rememorar y comentar específicamente el episodio de la Ascensión narrado en el capítulo uno de los Hechos. El siguiente pasaje del quinto sermón del pseudo San Agustín, en el que el narrador se pone en el lugar de los discípulos e imagina su reacción a la Ascensión del maestro, bastará para convencernos de la proximidad retórica del soneto de Boscán a este tipo de literatura y del tipo de equivalencias figurativas que esa proximidad favorece. El lamento que el barcelonés expresa en el segundo cuarteto de su poema guarda un obvio paralelo con la queja por abandono que expresan los discípulos en la escena que recrea el sermón, acercando así su figura a la de estos y la de Garcilaso a la del Cristo que, envuelto en una nube, asciende a los cielos:

Domine, inquiunt, quare nos derelinquis ascendens, qui nos elegisti in ripa praecedens? Domine, quando sumus verba tua super mel et favum eminus percepturi, et stillantis rorantisque gratiae balsamum de tuis labiis ac faucibus libaturi? Aut instrue quo ascendis, aut ne deseras cum ascendis. ${ }^{39}$

[Señor, preguntaron ellos, ¿por qué ascendiendo nos abandonas, habiéndonos elegido cuando caminaste delante de nosotros por la orilla? Señor, ¿cuándo escucharemos tus palabras, más dulces que la miel y la colmena, y degustaremos el bálsamo de tu gracia, que humedece y fluye de tus labios y tu boca? Bien dinos adónde subes o no nos abandones en tu ascenso.]

dime: ¿por qué tras ti no me llevaste cuando desta mortal tierra partiste?, ¿por qué, al subir a lo alto que subiste, acá en esta baxeza me dexaste? (CXXIX, 5-8)

La imagen cristomórfica de Garcilaso que Boscán cultiva en el soneto CXXIX tiene también, finalmente, importantes repercusiones macrotextuales dentro del diseño que Boscán elige para editar su poesía y la del toledano en 1543. La aparición del verso de Garcilaso al final del volumen viene a satisfacer en cierto modo el deseo de retorno que Boscán expresa en el segundo de sus sonetos in morte y confiere a este, por tanto, un papel profético y programático dentro del diseño general de Las Obras. El soneto contribuye, de esta manera, no sólo a mitificar y monumentalizar a Garcilaso a través del paralelo con Cristo, sino también a dotar de coherencia y cohesión interna a un volumen que, como Pedro Ruiz Pérez ha subrayado, está marcado por «un diseño editorial unitario [. . .] sin espacio para las variaciones ni los elementos descontextualizados» (2007:

39. Citado en O'Reilly (2010): 130. Ofrezco aquí mi traducción de este pasaje. Como O’Reilly señala, los sermones del pseudo San
Agustín aparecen frecuentemente publicados a lo largo del Quinientos con las obras del santo de Hipona. 
18). Este aspecto no debió de pasarle por alto tampoco a Herrera, cuya obsesión con los detalles organizativos y editoriales de la escritura es de sobra conocida. Para un poeta de esta suerte, que publica en 1582 una antología poética "con toda la perfección posible», ${ }^{40}$ la dimensión macrotextual del soneto CXXIX de Boscán debió resultar sin duda llamativa, lo que contribuyó, es posible que de forma decisiva, a garantizar ese estatus excepcional que el sevillano concede en las Anotaciones a las dos composiciones «en alabança de Garci Lasso» escritas por «su gran amigo Juan Boscán».

40. Blecua (1975): 17. 


\section{Bibliografía}

Argote de Molina, Gonzalo, Discurso sobre la poesía castellana, ed. Eleuterio F. Tiscornia, Madrid, Victoriano Suárez, 1926.

Arredondo, María Soledad, «El exceso de guerras, de peligros y destierro: de Garcilaso a Quevedo", Garcilaso y su época: del amor y la guerra, ed. José María Díez Borque y Luis Ribot García, Madrid, Sociedad Estatal de Conmemoraciones Culturales, 2003, 265-273.

ArmisÉn, Antonio, Estudios sobre la lengua poética de Boscán: la edición de 1543, Zaragoza, Libros Pórtico, 1982.

Bécares Botas, Vicente, Arias Montano y Plantino. El libro flamenco en la España de Felipe II, León, Secretariado de Publicaciones de la Universidad de León, 1999.

BLACK, Robert, «The Donation of Constantine: A New Source for the Concept of the Renaissance?», Language and Images of Renaissance Italy, ed. Alison Brown, New York, Oxford University Press, 1995, 51-85.

BlECUA, José Manuel, «Introducción», Fernando de Herrera: obra poética, Madrid, Anejo XXXII del BRAE, 1975.

Boscán, Juan, Juan Boscán: Obra completa, ed. Carlos Clavería, Madrid, Cátedra, 1999.

Brown, Gary J., "Fernando de Herrera and Lorenzo de' Medici: The Sonnet as Epigram", Romanische Forschungen, tomo 87, 2 (1975), 226-238.

Burke, Peter, The Renaissance Sense of the Past, New York, St. Martin's Press, 1969. Castiglione, Baldassarre, Il Cortigiano, vol. 1, Milano, Mondadori, 2002.

Cicerón, Marco Tulio, The Speeches, with an English Translation: Pro Archia poeta, Postreditum in senatu, Post reditum ad quirites, De domo sua, De aurispicum responsis, Pro Planico, London, Heinemann, 1923.

-, De re publica, De legibus with an English Translation, London, Heinemann, 1951.

—, La república, ed. Rafael Pérez Delgado, Madrid: Aguilar, 1979.

Clavería, Carlos, «Introducción», Juan Boscán: Obra completa, ed. Carlos Clavería, Madrid, Cátedra, 1999, 9-35.

Cochrane, Eric, Historians and Historiography in the Italian Renaissance, Chicago, University of Chicago Press, 1981.

Cruz Giráldez, Miguel, «Fernando de Herrera, ¿poeta épico frustrado?», Archivo Hispalense, 211 (1986), 7-14.

DagenaIs, John, y Greer, Margaret, «Decolonizing the Middle Ages: An Introduction", Journal of Medieval Studies, tomo 30, 3 (2000), 431-448.

De Armas, Frederick, "The Soundless Dance of the Passions: Boscán and Calderón's El pintor de su deshonra», The Modern Language Review, tomo 87, 4 (1992), 858-867.

Elliott, John H., y de la Peña, José Francisco, Memoriales y cartas del Conde Duque de Olivares, vol. 2, Madrid, Alfaguara, 1978. 
Estévez Molinero, Ángel, «Género y modalidad elegíaca en la poesía funeral del siglo XVII", La elegía. Encuentro internacional sobre poesía del Siglo de Oro, ed. Juan Alcina Rovira y Begoña López Bueno, Sevilla, Universidad de Sevilla, 1996, 261-292.

—, «Los descuidos de Garcilaso en la perspectiva de Herrera (con algunas notas sobre las 'necedades' en las Anotaciones)", Las Anotaciones de Fernando de Herrera. Doce Estudios, ed. Begoña López Bueno, Sevilla, Universidad de Sevilla, 1997, 135-156.

FINKELBERG, Margalit, «More on kleos aphthiton,» Classical Quarterly, tomo 5, 2 (2007), 341-50.

FowLER, Alastair, Kinds of Literature: An Introduction to the Theory of Genres and Modes, Cambridge, Harvard University Press, 1982.

Fox Morcillo, Sebastián, Teoría de la historia y teoría política en el siglo XVI: Sebastián Fox Morcillo, De historiae institutione dialogus (Diálogo de la enseñanza de la historia), ed. Antonio Cortijo Ocaña, Alcalá de Henares, Servicio de Publicaciones de la Universidad de Alcalá de Henares, 2000.

FrIedläNDER, Paul, Epigrammata: Greek Inscriptions in Verse from the Beginnings to the Persian Wars, Berkeley, University of California Press, 1948.

GaYlord, Mary, The Historical Prose of Fernando de Herrera, London, Tamesis Libros, 1971.

Grafton, Anthony, y Rice, Eugene, The Foundations of Early Modern Europe, 1460-1559, New York, Norton, 1994.

Hardison, O. B., The Enduring Monument: A Study of the Idea of Praise in Renaissance Literary Theory and Practice, Chapel Hill, The University of North Carolina Press, 1962.

Hay, Denys, "Flavio Biondo and the Middle Ages», Renaissance Essays, London, The Hambledon Press, 1988, 35-65.

Herrera, Fernando de. Fernando de Herrera. Anotaciones a la poesia de Garcilaso, ed. Inoria Pepe y José María Reyes, Madrid, Cátedra, 2001.

Homero, Ilíada, Madrid, Gredos, 2010.

—, La Odisea, Madrid, Gredos, 1982.

Kagan, Richard. "Clio and the Crown: Writing History in Hapsburg Spain», Spain, Europe, and the Atlantic World: Essays in Honour of John. H. Elliott, ed. Richard Kagan y Geoffrey Parker, Cambridge, Cambridge University Press, 1995, 73-99.

—, "Philip II, History, and the cronistas del rey», Philippus II Rex, ed. Fernando Chueca Goitia, Barcelona, Lunwerg Editores, 1998, 19-29.

KIng, Katherine C., Achilles: Paradigms of the War Hero from Homer to the Middle Ages, Berkeley, University of California Press, 1987.

LÁzaro Carreter, Fernando, «Dos notas sobre la poética del soneto en los 'Comentarios' de Herrera», Homenaje a F. Sánchez Castañer, Anales de literatura hispanoamericana 8 (1980), 315-321.

Lombardi, Elena, «I Desire therefore I am': Petrarch's Canzoniere Between the 
Medieval and the Modern Notion of Desire», Early Modern Medievalisms: The Interplay Between Scholarly Reflection and Artistic Production, ed. A. Montoya, Leiden y Boston, Brill, 2010, 19-43.

López Bueno, Begoña, «De poesía lírica y poesía mélica: sobre el género canción en Fernando de Herrera", Hommage à Robet Jammes, ed. Francis Cerdan, 3 vols, Toulouse, Presses Universitaires du Mirail, 1994, vol 2, 721-738.

-, "Las Anotaciones y los géneros poéticos»,_Las Anotaciones de Fernando de Herrera. Doce Estudios, ed. Begoña López Bueno, Sevilla, Universidad de Sevilla, 1997, 183-199.

Lorenzo, Javier, "Displacing Petrarch: Christomorphism and Exemplarity in Juan Boscán's Libro Segundo», Calíope, tomo 12,1 (2001), 25-36.

MaCrí, Oreste, Fernando de Herrera, Madrid, Gredos, 1972.

Martínez Ruiz, Francisco Javier, "Fernando de Herrera ante la crítica (19591996)", Las Anotaciones de Fernando de Herrera. Doce Estudios, ed. Begoña López Bueno, Sevilla, Universidad de Sevilla, 1997, 279-296.

Matas Caballero, J., «La pervivencia de modelos retóricos. Juan de Mena y la evolución poética en el Siglo de Oro», Gramática y Humanismo. Perspectivas del Renacimiento español, ed. Pedro Ruiz Pérez, Madrid, Ediciones Libertarias, 1993, 163-183.

McLaughlin, M. L., "Humanist Concepts of Renaissance and Middle Ages in the Treand Quattrocento", Renaissance Studies, tomo 2, 2 (1988), 131-142.

Medina, Francisco de, «El maestro Francisco de Medina a los letores»,_Fernando de Herrera. Anotaciones a la poesía de Garcilaso, ed. Inoria Pepe y José María Reyes, Madrid, Cátedra, 2001, 187-203.

Menéndez Pelayo, Marcelino, Juan Boscán, Antología de poetas liricos castellanos, vol. 13, Madrid, Librería y Casa Editorial Hernando, 1927.

Middlebrook, Leah, Imperial Lyric: New Poetry and New Subjects in Early Modern Spain, University Park, Pennsylvania State University Press, 2009.

Mitre Fernández, Emilio, "La historiografía sobre la Edad Media», Historia de la historiografía española, ed. José Andrés Gallego, Madrid, Ediciones Encuentro, 1999, 67-115.

Mommsen, Theodore, «Petrarch's Conception of the Middle Ages», Speculum, tomo 17, 2 (1942), 226-242.

Montero, Juan, «Las Anotaciones, del texto al lector», Las Anotaciones de Fernando de Herrera. Doce Estudios, ed. Begoña López Bueno, Sevilla, Universidad de Sevilla, 1997, 91-105.

Morales, Ambrosio de, La corónica general de España, Alcalá de Henares, Juan Ińiguez de Lequerica, 1574.

Morros, Bienvenido, "Las fuentes y su uso en las Anotaciones a Garcilaso", Las Anotaciones de Fernando de Herrera. Doce Estudios, ed. Begońa López Bueno, Sevilla, Universidad de Sevilla, 1997, 37-89.

—, Las polémicas literarias en la España del siglo XVI: a propósito de Fernando de Herrera y Garcilaso de la Vega, Barcelona, Quaderns Crema, 1998. 
—, «El tema de la guerra y la caza en Garcilaso», Garcilaso y su época: del amor y la guerra, ed. José María Díez Borque y Luis Ribot García, Madrid, Sociedad Estatal de Conmemoraciones Culturales, 2003, 227-240.

Nagy, Gregory, The Best of the Achaeans: Concepts of the Hero in Archaic Greek Poetry, Baltimore, The Johns Hopkins University Press, 1979.

Navarrete, Ignacio, Orphans of Petrarch: Poetry and Theory in the Spanish Renaissance. Berkeley: University of California Press, 1994.

O'Reilly, Terence, The Bible in the Literary Imagination of the Spanish Golden Age: Images and Texts from Columbus to Velázquez, Philadelphia, Saint Joseph's University Press, 2010.

Pacheco, Francisco, Libro de descripción de verdaderos retratos de ilustres y memorables varones, Sevilla, Diputación Provincial de Sevilla, 1985.

Pepe, Inoria, y Reyes, José María, «Introducción», Fernando de Herrera. Anotaciones a la poesía de Garcilaso, Madrid, Cátedra, 2001, 17-163.

Pérez Bowie, José A., «Pragmática de la lírica: la enunciación en primera persona ajena en la poesía funeraria y mitológica de los Siglos de Oro", Estado actual sobre los estudios de Siglo de Oro: actas del II Congreso Internacional de Hispanistas del Siglo de Oro, ed. Manuel García Martín, Salamanca, Ediciones Universidad de Salamanca, 1993, 777-786.

Petrarca, Francesco, Petrarch's Lyric Poems: The "Rime sparse» and Other Lyrics, Cambridge, Harvard University Press, 1976.

—, Africa, New Haven, Yale University Press, 1977.

Ruiz Pérez, Pedro, Libros y lecturas de un poeta humanista: Fernando de Herrera (1534-1597), Córdoba, Servicio de Publicaciones de la Universidad de Córdoba, 1997a.

—, "De la teoría a la práctica: modelos y modelización en Algunas Obras», Las Anotaciones de Fernando de Herrera. Doce Estudios, ed. Begoña López Bueno, Sevilla, Universidad de Sevilla, 1997b, 229-261.

—, "Las Obras de Boscán y Garcilaso: modelo editorial y modelo poético», $\mathrm{Ca}$ liope, tomo 13, 1(2007), 15-44.

SaAvedra-Fajardo, Diego, La república literaria, Salamanca, Anaya, 1967.

Sagrada Biblia, ed. Eloíno Nácar Fúster y Alberto Colunga Cueto, Madrid, Biblioteca de Autores Cristianos, 2005.

Schmidt, Rachel, «Herrera's Concept of Imitation as the Taking of Italian Spoils», Caliope, tomo 1, 1-2 (1995), 12-26.

Scodel, Joshua, The English Poetic Epitaph: Commemoration and Conflict from Jonson to Wordsworth, Ithaca, Cornell University Press, 1991.

SмIтн, Colin, «Fernando de Herrera and Argote de Molina», Bulletin of Hispanic Studies, 33 (1956), 63-77.

TAтE, Robert, «Italian Humanism and Spanish Historiography of the Fifteenth Century», Bulletin of the John Rylands Library, tomo 34, 1 (1952), 137-165.

Vega, Garcilaso, Obra poética y textos en prosa, ed. Bienvenido Morros, Barcelona, Crítica, 1995. 
Wofford, Susanne, The Choice of Achilles: The Ideology of Figure in the Epic, Stanford, Stanford University Press, 1992.

Woods, M. J., "Herrera's Voices», Medieval and Renaissance Studies on Spain and Portugal in Honour of P. E. Russell, ed. F. W. Hodcroft, Oxord, The Society for the Study of Medieval Language and Literature, 1981, 122-32. 